\title{
Sabañones en la consulta privada en épocas de COVID-19: a propósito de dos casos
}

\section{Chilblains in private practice in times of COVID-19: apropos of two cases}

\author{
Beatriz García de Acevedo Chávez,* María Graciela Guzmán Perera, * \\ Adriana Cecilia Gallegos Garza, ${ }^{\ddagger}$ Rogelio Antonio Sánchez Verin Lucio ${ }^{\ddagger}$
}

Citar como: García de Acevedo CB, Guzmán PMG, Gallegos GAC, Sánchez VLRA. Sabañones en la consulta privada en épocas de COVID-19: a propósito de dos casos. Acta Med Grupo Angeles. 2021; 19 (s1): s73-s75. https://dx.doi.org/10.35366/101032

\section{Resumen}

Los sabañones o pernio son una dermatosis acral eritematosa o violácea. La etiología es idiopática asociada al frío o secundaria a algunas enfermedades, como las del tejido conectivo. Dentro de las lesiones en piel asociadas a SARS-CoV-2 ocupa el segundo lugar. Los pacientes suelen ser pauci- o asintomáticos y la prueba de PCR o serología resulta negativa. En un estudio reciente, se observaron partículas virales en biopsia de piel por microscopía electrónica, confirmando la asociación. En México se desconoce la prevalencia de sabañones, los cuales suelen ser raros, ya que México es un país de clima templado. Se presentan dos casos de mujeres en tercera y cuarta década de la vida con estas inflamaciones en manos y pies, respectivamente, asintomáticas para COVID-19.

Palabras clave: Pernio, sabañones, COVID-19.

\section{Abstract}

Chilblains or pernio are an acral erythematous or violaceous dermatosis. The etiology is idiopathic related to cold weather or secondary to some diseases, connective tissue diseases among them. Pernio is the second most frequent dermatosis related to SARS-CoV-2. The patients are usually pauci or asymptomatic with both negative PCR or serology tests. In a recent study with electronic microscopy, viral particles were observed in a skin biopsy, confirming the association with the virus. The prevalence of chilblains in Mexico is unknown, they tend to be rare because of the warm weather. Two cases are presented, of women from the third and fourth decades of life, with chilblains in hands and feet respectively, asymptomatic with COVID-19.

Keywords: Pernio, chilblains, COVID-19.

\section{INTRODUCCIÓN}

Durante la pandemia de COVID-19 se ha reportado un incremento de lesiones purpúricas acrales idénticas a sabañones. ${ }^{1}$ Los sabañones son la segunda dermatosis más frecuentemente asociada a esa enfermedad viral. La mayoría de los pacientes son negativos para PCR de SARS-CoV-2 y menos del $50 \%$ tienen el antecedente de contacto con un enfermo con síntomas respiratorios o gastrointestinales. Se presentan dos casos de mujeres con estos malestares, sin antecedente de síntomas del contagio vírico.

\section{CASO 1}

Mujer de 22 años de edad, estudiante en Monterrey, sana, con antecedente de importancia: abuela materna con artritis reumatoide. Acudió por dermatosis de tres meses de evolución, localizada a dedos de manos, caracterizada por máculas eritematosas con aumento de volumen acompañadas de prurito ocasional (Figura 1). La paciente niega síntomas de vías aéreas o gastrointestinales sugestivos de infección por SARS-CoV-2. Estudios de laboratorio dentro de parámetros normales. Se tomó biopsia con dermatitis de interface

\footnotetext{
* Dermatóloga.

₹ Patólogo.
}

Hospital Ángeles Pedregal. Ciudad de México.
Correspondencia:

Beatriz García de Acevedo Chávez

Correo electrónico: beatriz_garciade@hotmail.com 
liquenoide, linfocitos perivasculares sin daño endotelial ni necrosis fibrinoide, que se extiende a la dermis profunda y perianexial, resultado compatible con sabañones. Para el prurito, el manejo fue sintomático con ebastina.

\section{CASO 2}

Mujer de 38 años de edad, con antecedente de fenómeno de Raynaud desde los 18 años. Acude por dermatosis localizada a dedos de los pies, distinguida por incremento de volumen y eritema acompañado de prurito, ocasionalmente intenso, de días de evolución (Figura 2). Negó síntomas sugestivos de COVID-19 o interacción con alguna persona infectada. Se solicitaron estudios de laboratorio.

\section{DISCUSIÓN}

Los sabañones son una inflamación localizada a la piel, que se presenta como máculas eritematosas a purpúricas con aumento de volumen en pies y/o manos afectando frecuentemente los dedos. ${ }^{1,2}$ Se clasifican en primarios o idiopáticos, relacionados al frío; y secundarios, asociados a padecimientos del tejido conectivo (lupus, enfermedad de Behcet, síndrome antifosfolípido, artritis reumatoide, síndrome de Sjogren), criopatías, trastornos neoplásicos o linfoproliferativos, estados de hiperviscosidad sanguínea, alteraciones genéticas (síndrome de Aicardi-Goutières, deficiencia de IRAK). ${ }^{1,3}$

Entre las lesiones de piel asociadas a SARS-CoV-2, el pernio ocupa el segundo lugar, superado únicamente por maculopapulares en la serie española con $19 \%$ y en la internacional con 716 casos de 31 países con 18\%., ${ }^{4,5}$ En Europa y Estados Unidos, se han reportado al menos 995

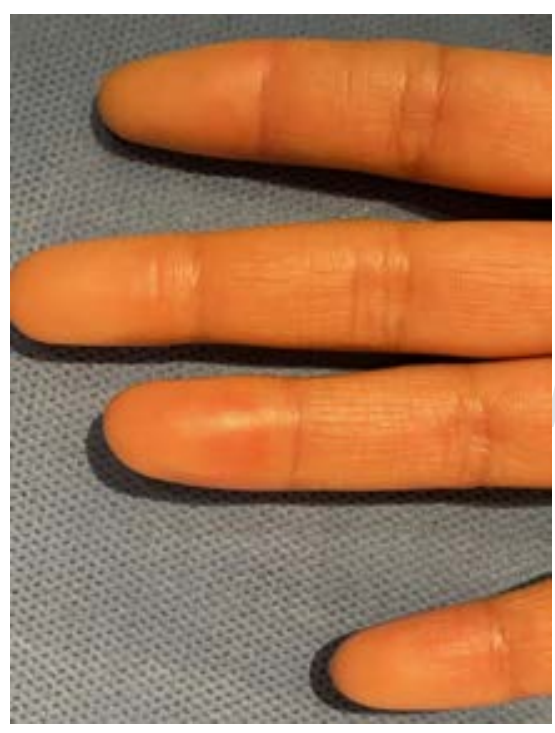

Figura 1:

Sabañones en manos.

Dermatosis localizada a manos caracterizado por eritema y aumento de volumen.

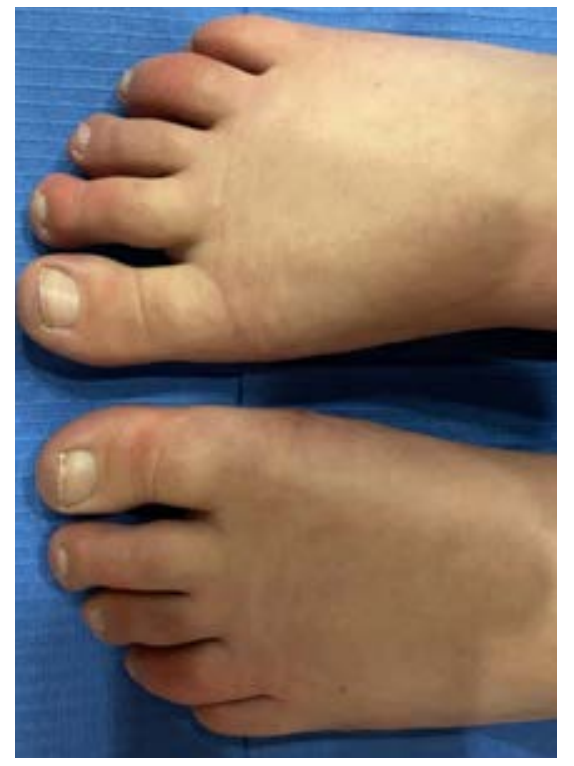

incidencias de sabañones en 14 series con un número mínimo de 10 pacientes. ${ }^{6}$ Los primeros eventos descritos fueron en el pico de la pandemia en primavera en Europa, donde llamó la atención observar tales eritemas en una época del año donde no hace frío y por lo tanto no se presentan. En este país, por la situación geografía y el clima favorecido no se suelen ver episodios de perniosis y su prevalencia se desconoce.

Los estudios que se exponen son de mujeres jóvenes, aparentemente sanas, sin sintomatología sugestiva de COVID-19, situación que concuerda con lo reportado en la literatura. En un estudio francés retrospectivo por cuestionario se recopilaron 311 casos de manifestaciones acrales con edad media de 25.7 años (18-39), 65\% con cuadros típicos de sabañones, $49 \%$ sin síntomas de coronavirus. Sólo $6 \%$ de los 121 a quienes se les hizo prueba PCR fue positiva y únicamente $7 \%$ con serología positiva (10 de 150). ${ }^{6}$ Debido a que, en la mayoría de las series y reportes de eventos, el porcentaje con síntomas o pruebas positivas de SARS-CoV-2 es bajo, se ha llegado a dudar de su asociación como lo sugiere un estudio belga con 31 pacientes con tales inflamaciones, donde realizaron inmunohistoquímica y PCR para este virus en 22 biopsias de piel, todas negativas. ${ }^{7}$ En este estudio concluyen que las lesiones son secundarias a cambio en el estilo de vida. Un mes después, el grupo español publica una inmunohistoquímica para SARS-CoV-2 en la biopsia de siete niños de su serie de incidentes estudiados, la cual fue positiva en células endoteliales y epiteliales de glándulas ecrinas. Observaron una de estas biopsias al microscopio electrónico, encontrando partículas virales en el citoplasma de células endoteliales. Concluyeron que, la presencia de este 
germen en el endotelio de vasos dérmicos de biopsias de piel de niños con sabañones, confirma que estos estragos son manifestaciones de COVID-19. ${ }^{3}$

El diagnóstico es clínico, las lesiones se pueden acompañar de dolor en $7.32 \%$ o prurito en $9.41 \%$ como en los casos mostrados. ${ }^{1}$ En la biopsia de piel de los sabañones se observa infiltrado linfocitario angiocéntrico y ecrinotrópico, edema papilar, degeneración vacuolar de la basal y hallazgos de vasculitis linfocitaria, siendo la distribución del infiltrado alrededor de las glándulas ecrinas lo más característico. ${ }^{1,2}$ La biopsia de dicha paciente corrobora el diagnóstico clínico.

Se han propuesto, como mecanismos fisiopatológico de este eritema en COVID-19: la afección endotelial, que lleva a daño vascular y trombosis con deterioros acroisquémicos, o bien el aumento de la expresión de interferón tipo 1 que se ha descrito el virus provoca. ${ }^{1,3}$

Dentro de los diagnósticos diferenciales, se debe pensar en sabañones asociados a lupus; en la histología, el infiltrado periecrino y la ausencia de mucina en la dermis es más indicativo de pernio idiopático, además de que el pernio de lupus tiene un curso más crónico, no tiene relación con el frío y suele haber alteraciones de laboratorio. ${ }^{1}$ En ambas ocasiones se solicitaron anticuerpos antinucleares y factor reumatoide.

El manejo tradicional de los eritemas ha sido evitar el frío y el cigarro. Se han empleado calcio antagonistas, en particular nifedipino, esteroides tópicos, pentoxifilina, hidroxicloroquina, nitroglicerina y hasta acupuntura. ${ }^{2}$ En los casos asociados a COVID-19, el manejo ha sido con analgésicos orales para el dolor y antihistamínicos para el prurito. ${ }^{1}$

Se tiene la hipótesis de que la RT PCR para SARS-CoV-2 es negativa porque la presencia de este tipo de inflamación es una manifestación tardía de COVID-19, momento en el que la prueba ya es negativa. ${ }^{8}$ Los sabañones resuelven espontáneamente en un lapso de 8 semanas y tienen un excelente pronóstico.

\section{REFERENCIAS}

1. Andina D, Noguera-Morel L, Bascuas-Arribas M, Gaitero-Tristán J, Alonso-Cárdenas JA, Escalada-Pellitero $\mathrm{S}$ et al. Chilblains in children in the setting of COVID-19 pandemic. Pediatr Dermatol. 2020; 37 (3): 406-411. doi: 10.1111/pde.14215.

2. Nyssen A, Benhadou F, Magnée M, André J, Koopmansch C, Wautrecht JC. Chilblains. Vasa. 2020; 49 (2): 133-140. doi: 10.1024/0301-1526/a000838.

3. Colmenero I, Santoja C, Alonso RM, Noguera-Morel L, HernándezMartín A, Andina D et al. SARS-CoV-2 endothelial infection causes COVID-19 chilblains: histopathological, immunohistochemical and ultrastructural study of seven paediatric cases. Br J Dermatol. 2020; 183 (4): 729-737. doi: 10.1111/BJD.19327.

4. Freeman EE, MCMahon DE, LipoffJB, Rosenbach M, Kovarik C, Desai SR et al. The spectrum of COVID 19 associated dermatologic manifestations: an international registry of 716 patients from 31 countries. J Am Acad Dermatol. 2020; 83: 1118-1129. doi: 10.1016/j.jaad.2020.06.1016.

5. Galván CC, Catalá A, Carretero HP, Fernández NA, Rodriguez-Villa LI, Navarro FR et al. Classification of the cutaneous manifestation of COVID-19: a rapid prospective nationwide consensus study in Spain with 375 cases. Br J Dermatol. 2020; 29. doi: 10.1111/bjd.19163.

6. Le Cleach L, Dousset L, Assier H, Fourati S, Barbarot S, Boulard C et al. Most chilblains observed during the COVID-19 outbreak occur in patients who are negative for COVID-19 on polimerase chain reaction and serology testing. Br J Dermatol. 2020; 183 (5): 866-874. doi: 10.1111/bjd.19377.

7. Herman A, Peeters C, Verroken A, Tromme I, Tennstedt D, Marot L. Evaluation of chilblains as a manifestation of COVID-19 pandemic. JAMA Dermatol. 2020; 156 (9): 998-1003. doi: 10.1001/ jamadermatol.2020.2368.

8. Mohan V, Lind R. Chilblains in COVID-19 infection. Cureus. 2020; 12 (7): e9245. doi: 10.7759/cureus.

Conflicto de intereses: Sin conflicto de intereses. 